\title{
THE DESIGN AND PRODUCT OF NATIONAL 1:10 00000 CARTOGRAPHIC DATA OF TOPOGRAPHIC MAP
}

\author{
Guizhi Wang (wangmiaojie@163.com) \\ National Geomatics Center of China, People's Republic of China
}

\section{Commission II, WG II/3}

KEY WORDS: database-driven Mapping; cartographic database; 1:10 00000 scale topographic map; database structure; national fundamental geographic information database; representation rule

\begin{abstract}
:
National administration of surveying, mapping and geoinformation started to launch the project of national fundamental geographic information database dynamic update in 2012. Among them, the 1:50000 database was updated once a year, furthermore the 1:250000 database was downsized and linkage-updated on the basis. In 2014, using the latest achievements of 1:250000 database, comprehensively update the 1:1000000 digital line graph database. At the same time, generate cartographic data of topographic map and digital elevation model data. This article mainly introduce national 1:1000000 cartographic data of topographic map, include feature content, database structure, Database-driven Mapping technology, workflow and so on.
\end{abstract}

\section{INTRODUCTION}

National 1:1000000 scale database is an important part of the national fundamental geographic information database. It plays a very important role in the national economic construction, social development, scientific research and national defense security. National 1:1000000 cartographic data of topographic map is mainly used for national macro planning, foundation map of small scale thematic map such as national geological map, soil map, etc.

National 1:1000000 database was originally built in 1994 and was updated in 2002. More than a decade, with the improving of the geographic information technology and large changing in related technical standards and specifications, existing 1:1000000 database is not unified with national 1:50000 and 1:250000 database in data content, data processing, product structure and data model. Therefore, urgent need to update 1:1000000 database, realize unity and cohesion of the national fundamental geographic information database.

To meet the national multiple needs, enrich the content and its products of the national fundamental geographic information database, National administration of surveying, mapping and geoinformation commissioned National Geomatics Center of China(NGCC for short) to organize and produce national 1 : 1000000 cartographic data of topographic mapping and established integration database in 2014. Cartographic data was produced on the basis of national 1:1000000 fundamental topographic database, using database-driven topographic mapping technology.
National 1:1000000 database has the same database structure and data model as national 1:250000, 1:50000 database. They have consistent data hierarchy, naming, attribute definition and so on. Therefore, realized coordination and connection between different databases.

According to standard framing of map, national 1:1000000 database includes 77 sheets. The data range and small sample plot as shown in figure 1 and 2:

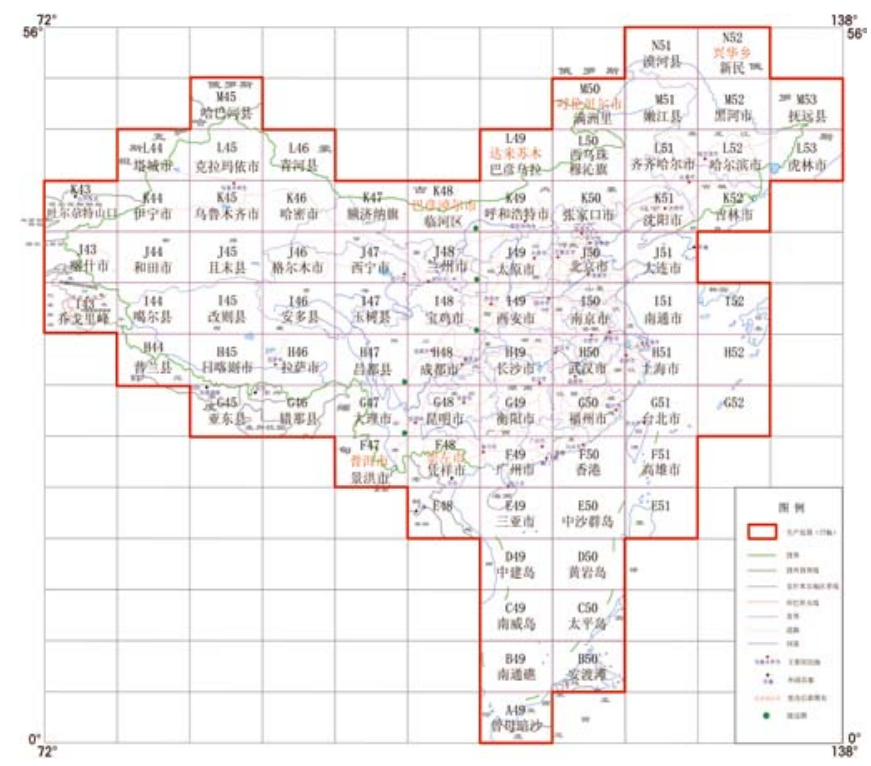

Figure 1. Data range of 1:1000000 topographic map

Supported by the National Fundamental Geographic Information Database Dynamic Updating Project of the National Administration of Surveying, Mapping and Geoinformation of China. 


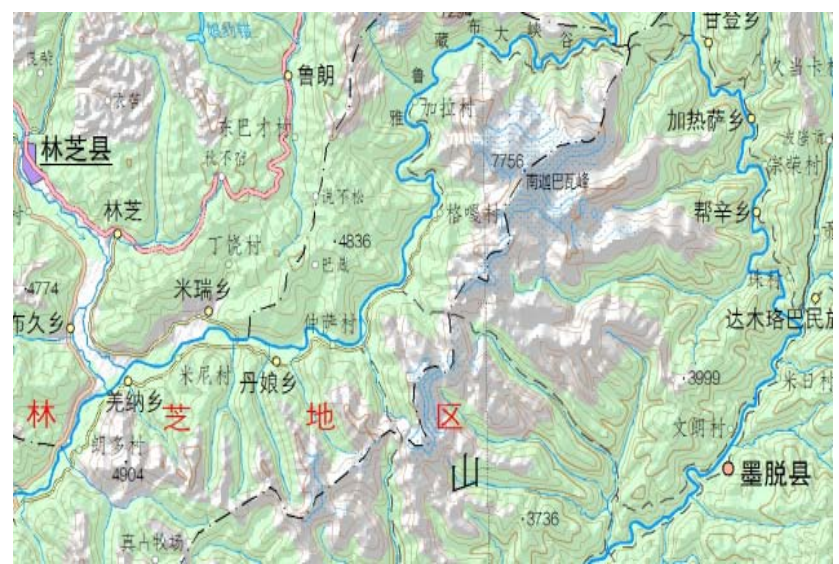

Figure 2. Small sample plot of 1:1000000 topographic map

\section{THE STRUCTURE AND CONTENT OF DATABASE}

In the national 1:10 00000 integration database, cartographic database are integrately stored with topographic database. Topographic database is base, by extension mapping information, generate cartographic data using database-driven topographic mapping technology. Using representation mechanism, created a map symbol library. The mapping information was stored in the attribute items of terrain database. Cartographic database relate to topographic database each other in features level, symbols level, notes level. Realized the integration storage of Cartographic database and topographic database.

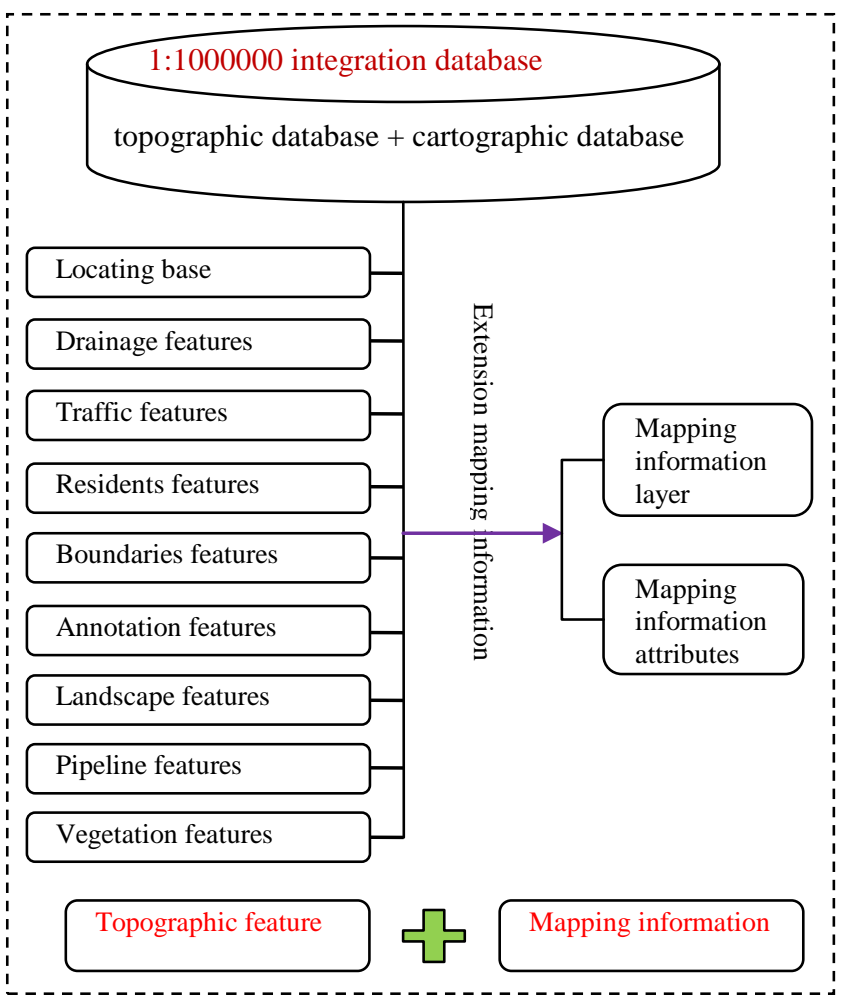

Figure 3. Structure and content of integration database

The national 1:10 00000 database includes 9 categories features such as locating base, drainage features, traffic features, residents features, boundaries features, annotation features, landscape features, pipeline features, vegetation features. The structure and content of integration database as shown in figure 3:

Specific content and index is as follows:

\subsection{Water system and ancillary facilities}

Includes all the double rivers and ditches, single river high than six levels, main canal, lakes and reservoirs high than four levels, river structure line, important ancillary facilities, coastline, sea. According to feature density, properly selected other rivers, lateral canal and secondary ancillary facilities .

\subsection{Residents and ancillary facilities}

Includes all the residents high than county level, the government headquarter places high than municipal level, the famous Great Wall, significant independent features, a large area of aquaculture farms, etc. According to feature density, properly selected ordinary housing, ger, grazing points, independent features, etc. Other government headquarter places are not selected.

\subsection{Traffic and ancillary facilities}

Includes all the railway, national highway, provincial roads, county roads, civil airport as well as all the subway, light rail, magnetic levitation, expressway in large area residents, and all the car bridge, tunnel above main rivers, railways, highways. According to feature density, properly selected ports, navigation marks , etc.

\subsection{Boundaries and administrative divisions}

Includes all the foreign national administrative areas, the exclusive economic zones, China's county level administrative regions as well as foreign national boundaries, China's county boundaries and above, the baselines and baseline points of our territorial sea.

\subsection{Pipe line}

National submarine cables are selected as far as possible.

\subsection{Landscape}

Select contours according to 500 meter interval and increase 50 meter, 200 meter contour. According to feature density, properly selected longer ravines, steep cliffs, embankment, moat, etc. The natural landscape elements of tall, famous, important, reflect landscape characteristic should be selected.

\subsection{Place names}

Includes all the administrative place name of township residents and above. According to feature distribution density, properly selected villages names and other names.

\subsection{Vegetation and soil}

Large important vegetation, sandy land, ice and snow, a steep rock, rock, soil elements should be selected. According to feature density, properly selected small garden land in sparse area and forest land concentration distribution area. 


\section{DATA LAYERS AND ATTRIBUTE ITEMS}

The national 1:1000000 integration database includes 9 categories features and 29 layers. It uses geo-database data format in ArcGIS and its meanwhile reached 2014. It adopts the 2000 national geodetic coordinate system and 1985 national elevation datum.

In each of the data layer, according to characteristics of elements, design attributes table structure and define attribute items. The detailed content is as following table I:

TABLE I. DATA LAYERS AND ATTRIBUTE ITEMS

\begin{tabular}{|c|c|c|c|c|c|}
\hline 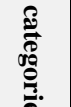 & \multicolumn{2}{|c|}{$\begin{array}{l}\text { data layers } \\
\text { and naming }\end{array}$} & $\begin{array}{c}\text { geometric } \\
\text { type }\end{array}$ & $\begin{array}{c}\text { attribute } \\
\text { items }\end{array}$ & describe \\
\hline 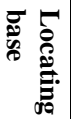 & $\begin{array}{l}\text { Coordin } \\
\text { ate grid }\end{array}$ & CPTL & line & GB & $\begin{array}{l}\text { international standard } \\
\text { category codes }\end{array}$ \\
\hline \multirow{21}{*}{ 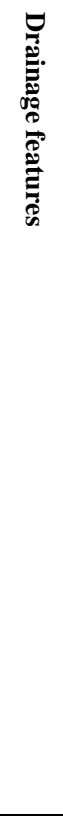 } & \multirow{7}{*}{$\begin{array}{l}\text { Drainage } \\
\text { (area) }\end{array}$} & \multirow{7}{*}{ HYDA } & \multirow{7}{*}{ area } & GB & category codes \\
\hline & & & & HYDC & Drainage name code \\
\hline & & & & NAME & name \\
\hline & & & & WQL & Water quality \\
\hline & & & & VOL & $\begin{array}{c}\text { large/medium/small } \\
\text { reservoirs }\end{array}$ \\
\hline & & & & PERIOD & water seasons \\
\hline & & & & TYPE & type \\
\hline & \multirow{4}{*}{$\begin{array}{l}\text { Drainage } \\
\text { (line) }\end{array}$} & \multirow{4}{*}{ HYDL } & \multirow{4}{*}{ line } & GB & category codes \\
\hline & & & & HYDC & Drainage name code \\
\hline & & & & NAME & name \\
\hline & & & & PERIOD & water seasons \\
\hline & \multirow{4}{*}{$\begin{array}{c}\text { Drainage } \\
\text { (point) }\end{array}$} & \multirow{4}{*}{ HYDP } & \multirow{4}{*}{ point } & GB & category codes \\
\hline & & & & NAME & name \\
\hline & & & & TYPE & type \\
\hline & & & & ANGLE & angle \\
\hline & \multirow{6}{*}{$\begin{array}{l}\text { Drainage } \\
\text { ancillary } \\
\text { facilities }\end{array}$} & \multirow{2}{*}{ HFCA } & \multirow{2}{*}{ area } & GB & category codes \\
\hline & & & & NAME & name \\
\hline & & \multirow{2}{*}{ HFCL } & \multirow{2}{*}{ line } & GB & category codes \\
\hline & & & & NAME & name \\
\hline & & \multirow{2}{*}{ HFCP } & \multirow{2}{*}{ point } & GB & category codes \\
\hline & & & & NAME & name \\
\hline \multirow{10}{*}{ 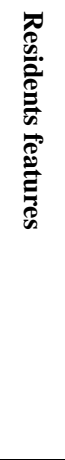 } & \begin{tabular}{|c} 
Resident \\
s \\
(area) \\
\end{tabular} & RESA & area & GB & category codes \\
\hline & \multirow{2}{*}{$\begin{array}{c}\text { Resident } \\
\text { s } \\
\text { (point) }\end{array}$} & \multirow{2}{*}{ RESP } & \multirow{2}{*}{ point } & GB & category codes \\
\hline & & & & ANGLE & angle \\
\hline & \multirow{7}{*}{$\begin{array}{c}\text { Resident } \\
\text { s } \\
\text { ancillary } \\
\text { facilities }\end{array}$} & \multirow{2}{*}{ RFCA } & \multirow{2}{*}{ area } & GB & category codes \\
\hline & & & & NAME & name \\
\hline & & \multirow{2}{*}{ RFCL } & line & GB & category codes \\
\hline & & & & NAME & name \\
\hline & & & & GB & category codes \\
\hline & & RFCP & point & NAME & name \\
\hline & & & & TYPE & type \\
\hline & & & & GB & category codes \\
\hline 焉 & Railway & LRRL & line & $\mathrm{RN}$ & road number \\
\hline$\vec{\nabla}$ & (line) & & & NAME & name \\
\hline 苋 & & & & TYPE & type \\
\hline$\overline{7}$ & & & & GB & category codes \\
\hline & Road & LRDL & line & $\mathrm{RN}$ & road number \\
\hline & (line) & & & NAME & name \\
\hline & & & & RTEG & road technical level \\
\hline
\end{tabular}

\begin{tabular}{|c|c|c|c|c|c|}
\hline & & & & TYPE & type \\
\hline & \multirow{9}{*}{$\begin{array}{c}\text { Traffic } \\
\text { ancillary } \\
\text { facilities }\end{array}$} & \multirow{3}{*}{ LFCL } & \multirow{3}{*}{ line } & GB & category codes \\
\hline & & & & NAME & name \\
\hline & & & & BRGLEV & layer number \\
\hline & & \multirow{6}{*}{ LFCP } & \multirow{6}{*}{ point } & GB & category codes \\
\hline & & & & $\mathrm{RN}$ & road number \\
\hline & & & & NAME & name \\
\hline & & & & PERIOD & passage seasons \\
\hline & & & & BRGLEV & layer number \\
\hline & & & & ANGLE & angle \\
\hline 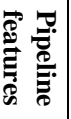 & $\begin{array}{l}\text { Pipeline } \\
\text { (line) }\end{array}$ & PIPL & line & GB & category codes \\
\hline \multirow{10}{*}{ 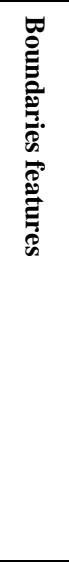 } & \multirow{2}{*}{$\begin{array}{c}\text { Administra } \\
\text { tive } \\
\text { (area) }\end{array}$} & \multirow{2}{*}{ BOUA } & \multirow{2}{*}{ area } & PAC & $\begin{array}{c}\text { Administrative } \\
\text { division code }\end{array}$ \\
\hline & & & & NAME & name \\
\hline & $\begin{array}{c}\text { Administra } \\
\text { tive } \\
\text { (line) } \\
\end{array}$ & BOUL & line & GB & category codes \\
\hline & \multirow{2}{*}{$\begin{array}{c}\text { Administra } \\
\text { tive } \\
\text { (point) }\end{array}$} & \multirow[b]{2}{*}{ BOUP } & \multirow[b]{2}{*}{ point } & GB & category codes \\
\hline & & & & BNO & $\begin{array}{c}\text { Number of Boundary } \\
\text { tablets }\end{array}$ \\
\hline & \multirow{2}{*}{$\begin{array}{l}\text { Region } \\
\text { (area) }\end{array}$} & \multirow{2}{*}{ BRGA } & \multirow{2}{*}{ area } & GB & category codes \\
\hline & & & & NAME & name \\
\hline & $\begin{array}{c}\text { Region } \\
\text { (line) }\end{array}$ & BRGL & line & GB & category codes \\
\hline & \multirow{2}{*}{$\begin{array}{l}\text { Region } \\
\text { (point) }\end{array}$} & \multirow{2}{*}{ BRGP } & \multirow{2}{*}{ point } & GB & category codes \\
\hline & & & & NAME & name \\
\hline \multirow{7}{*}{ 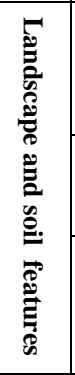 } & \begin{tabular}{|c|} 
Landsca \\
pe and \\
soil \\
(area) \\
\end{tabular} & TERA & area & GB & category codes \\
\hline & \multirow{2}{*}{\begin{tabular}{|l|} 
Landsca \\
pe \\
(line) \\
\end{tabular}} & \multirow{2}{*}{ TERL } & \multirow{2}{*}{ line } & GB & category codes \\
\hline & & & & ELEV & Elevation value \\
\hline & \multirow{4}{*}{$\begin{array}{l}\text { Landsca } \\
\text { pe } \\
\text { (point) }\end{array}$} & \multirow{4}{*}{ TERP } & \multirow{4}{*}{ point } & GB & category codes \\
\hline & & & & ELEV & Elevation value \\
\hline & & & & NAME & Name \\
\hline & & & & ANGLE & Angle \\
\hline \multirow{2}{*}{ 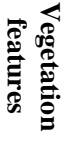 } & \multirow{2}{*}{$\begin{array}{l}\text { Vegetati } \\
\text { on } \\
\text { (area) }\end{array}$} & & & GB & category codes \\
\hline & & VEGA & ared & TYPE & type \\
\hline & & & & NAME & name \\
\hline & & & & PINYIN & Chinese pinyin \\
\hline 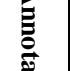 & $\begin{array}{l}\text { Resident } \\
\text { s names }\end{array}$ & AGNP & point & CLASS & $\begin{array}{c}\text { Place names category } \\
\text { codes } \\
\end{array}$ \\
\hline . & & & & GNID & Name code \\
\hline $\overrightarrow{0}$ & & & & XZNAME & Township name \\
\hline 苋 & & & & NAME & name \\
\hline 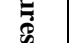 & place & AANP & point & PINYIN & Chinese pinyin \\
\hline & names & & & CLASS & $\begin{array}{l}\text { Place names category } \\
\text { codes }\end{array}$ \\
\hline
\end{tabular}

The table above is the physical structure for cartographic database. When map displaying, need to redesign the logical structure and new hierarchical layers of cartographic data, and stacking sequence of mapping data layers.

Generally, they overlay in turn from top to bottom by decorative elements, annotation notes, point symbols, line symbols, area symbols. However, some line symbols must be placed under the area symbols, and some combination symbols need to split into different logic layer in order to solve the problem of map symbol gland and conflict each other. For example, contours 
must be put below the area drainage pattern symbols; vegetation symbol needs to be split into the logic layers of dot, line, area; tunnel symbol needs to be split into the logic layers of point and line, and so on.

\section{INTEGRATION ESTABLISH OF TOPOGRAPHIC DATABASE AND CARTOGRAPHIC DATABASE}

Considering integration storage and management of topographic database and cartographic database, and the application requirement of linkage update, the national 1:10 00000 cartographic database adopted quick mapping method based on topographic database, which has been greatly increased production efficiency.

Through building closely related between topographic database and cartographic database about element level, symbol level, annotation level, make topographic database and cartographic database stored in the same database. Thus, laid the groundwork for fast linkage update between topographic database and cartographic database in future.

The technology methods and steps of integration cartographic database establishing as shown in figure 3 :

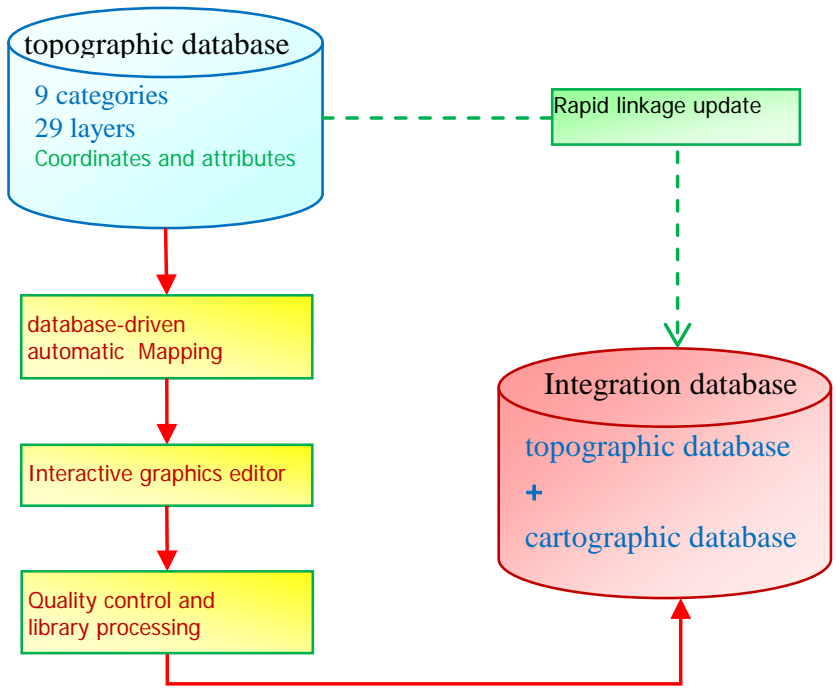

Figure 4. The technology methods and steps of integration cartographic database establishing

\section{1 database-driven automatic Mapping}

First, according to the schema specification, established the map symbol library system and drawing character system. Then, using technology of database-driven mapping, create representation rules based on topographic database. Through automatically configurating map symbols and intelligently adjusting feature relations, realize the rapid and automatic topographic map mapping. Thus, built preliminary cartographic database that also need further editing and processing.

In order to make full use of the production strength of surveying and mapping, and meet the needs of the distributed production, need to extract the framing cartographic data library from the preliminary cartographic database. The framing cartographic data library was known as the primary cartographic data products. Then, distribute the primary cartographic data products to Provincial bureaus of surveying and mapping .

\subsection{Interactive graphics editor}

The primary cartographic data products also need to interactively edited and processed. Aartificially adjust map symbols and drawing characters that are gland or conflict each other. Make the element relations coordinate and the levels distinct, correctly reflect the geographical characteristics of drawing area. Avoid the unreasonable phenomenon between features such as conflict, gland, dislocation, etc.

General management principles are: natural elements before artificial elements, major elements before secondary elements, other elements after independent features.

For example, Drainage system is one of the most basic elements of geographical environment. It has skeleton effect on the relationship processing and expression of the map elements. Thus, need to faithfully reflect the general characteristics of the spatial distribution, especially highlight the carcass traits of rivers, and deal well the relationship with the human elements such as transportation networks, boundaries, etc. When roads and rivers in parallel, need to first ensure river location accurate, then move the position of the path, but should maintain the relative position with rivers unchanged.

Landform is the basic elements of the natural geographical environment. It constitutes the natural foundation of other elements with drainage together on the map. The coordinate relationship should be deal with well between landscape and drainage. River should flow along the bottom of valley from high to low.

\subsection{Quality control and library processing}

Before the single framing cartographic data entering into the database, need to perform a comprehensive quality inspection for all cartographic data products, and deal with the problems found. Make products quality meet the requirements of database.

During the overall process of cartographic data production, have practiced strict quality control and check including 2-level checking and 1-level accepting so that ensured the quality of cartographic data products. They are as follow: Production operation departments implement the process check for middle achievements such as everyday back-up and comparative analysis as well as the total check for final achievements; As the competent administration of production operation department, provincial bureau of surveying and mapping, is responsible for the batch products quality by means of sampling detailed survey; As project organization administration, NGCC is responsible for the overall quality control before entering into database, and carries through the quality checking and accepting by the way of combining sampling detailed survey with total number outline check.

According to the quality control contents and indicator system of cartographic data, aiming to the specific status of foundation geographic data and cartographic representation data, as well as current production operating model of foundation surveying and mapping, utilized the combinative technical method of software automatic inspection, man-machine interactive inspection, manual comprehensive inspection for quality control.

Finally, using the integration storage and management model of topographic data and cartographic data, built integrated database system of large area continuous seamless storage. After completing the integration database, the follow-up data update can be based on two sets of closely related data. using 
incremental updates data of topographic database, the cartographic database is fast linkage-updated with topographic database.

\section{CONCLUSIONS AND PROSPECTS}

In order to enlarge the application range of national 1:1000000 database, better meet user requirements, improve the using efficiency, the national 1:1000000 integration database was positioned as public version. this database can openly provide services to the outside, and be able to meet the wide range of application demand.

The surface expression of cartographic data in this project referenced to the original 1:1000000 paper topographic map. At the same time, according to the characteristic of public version map, Map symbols were optimized and adjusted. Landscape with dizzy adamantly, and through highlighting the main symbols of map elements, make the map more legibility and beautiful. So the national 1:1000000 integration database also can meet the application requirements of geographic base map.

According to the series products model, data model and related technical index of new national 1:50000, 1:250000 database, designed the product model, expression content, technical indicators, etc of national 1:1000000 database. makes the national basic scale series database to unified each other, easy to fast linkage-update database in the future.

Using database-driven mapping technology, constructed integration storage model of terrain data and graphics data. The terrain data and graphics data seamlessly stored in the same database, which not only greatly reduce the data redundancy, but also make them closely associated between elements level, symbols level, notes level. Realized the integration management and linkage update of the cartographic data and topographic data, greatly reduce the cost of database maintenance and continuously updated.

Since 2008, NGCC studied and established a set of technical processes and software system for producing cartographic data based on topographic database. They have been successfully applied to the quickly producing in national 1:50000, 1:250000, 1:1000000 cartographic data of topographic map. Up to now, national 1:50000 cartographic database is updated three times, national 1:250000 cartographic database is updated one times, national 1:1000000 cartographic database is updated one times. The results show: improved the work efficiency of integrated cartographic database establishing and guaranteed the products quality of cartographic data of topographic map. In the future, this set of technical processes and software system can be used in quickly producing of other scale cartographic data. It also has important lead significance to carry out the national large-scale cartographic data production(for example, 1:10000 at the provincial level) and push the rapid development of standardized cartographic data products.

\section{ACKNOWLEDGMENT}

The author would like to express appreciations to colleagues in our department for their valuable comments and other helps.

\section{REFERENCES}

[1] The overall design scheme of national fundamental geographic information database dynamic update project, (trial draft), the National Administration of Surveying, Mapping and Geoinformation of China, 2014.4.

[2] The overall design scheme of national 1:1000000 database update, (trial draft), the National Geomatics Center of China, 2014.5.

[3] The technical regulations of national 1:1000000 terrain database update, (trial draft), the National Geomatics Center of China, 2014.5.

[4] The production technical regulations of national 1:1000000 cartographic data of topographic map, (trial draft), the National Geomatics Center of China, 2014.5.

[5] Data dictionary for fundamental geographic information features-Part 4: Data dictionary for fundamental geographic information features of 1:250000 1:500000 1:1000000 scale, GB/T 20258.4-2007.

[6] Common map symbols for the public geographical information, GB/T 24354-2009.

[7] Cartographic symbols for national fundamental scale maps-Part 4: Specifications for cartographic symbols 1:250000 1:500000 1:1000000 topographic maps, GB/T 20257.4—2007.

[8] WANG Guizhi, SHANG Yaoling, LIU Jianjun, WU Chenchen, The Quality Control of national 1:50000 cartographic data of topographic map, http://ieeexplore.ieee.org/search/searchresult.jsp?reload=tr ue\&newsearch=true\&queryText=The+Quality+Control+of +national+1\%3A50000+cartographic+data+of+topographi $c+\operatorname{map} \& x=49 \& y=16$.

[9] WANG Donghua, SHANG Yaoling, JIU Jianjun, Discussion of Database-driven Topographic Mapping Technology, Geomatics World, 2012.4(2). P6-9.

[10] Specifications for quality inspection and acceptance of surveying and Mapping products, GB/T 24356-2009.

[11] CHEN Jun, WANG Donghua, SHANG Yaoling, The Overall Design Research and Technological Innovation of National 1:50000 Fundamental Geographic Information Database Updating Project, surveying and mapping academic journal, 2010.2(1), P710. 